\title{
Erratum to: Engineering for Human-Computer Interaction
}

\author{
Stéphane Chatty ${ }^{1}$ and Prasun Dewan ${ }^{2}$ \\ 1 Centre d'Études de la Navigation Aérienne, France \\ 2 University of North Carolina at Chapel Hill, USA
}

\section{Erratum to:}

S. Chatty and P. Dewan (Eds.)

Engineering for Human-Computer Interaction

DOI: $10.1007 / 978-0-387-35349-4$

The book was inadvertently published with an incorrect name of the copyright holder. The name of the copyright holder for this book is: (c) IFIP International Federation for Information Processing. The book has been updated with the changes. 